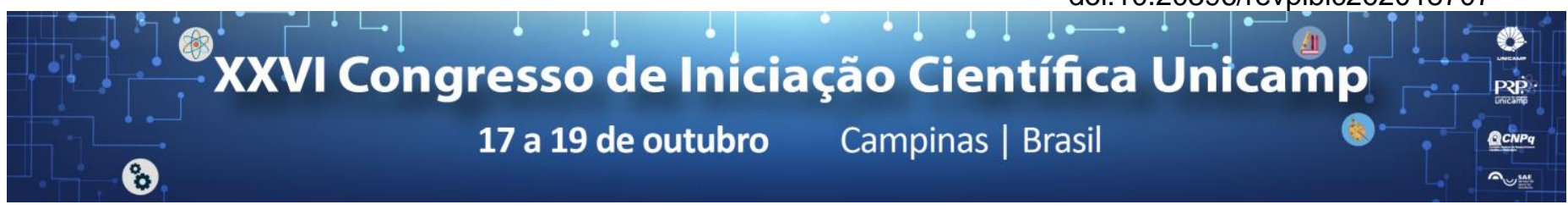

\title{
Componente "B" na Biorremediação de Solo Contaminado por Benzeno e Tolueno
}

\author{
Julia F. Pizi ${ }^{\star}$ André R. de Almeida, Naomi Torigoe, Henrique D. Figueiredo, Cassiana Maria Reganhan Coneglian
}

\section{Resumo}

O petróleo e seus derivados são cada vez mais consumidos, sendo importantes fontes de energia e responsáveis pela realização de atividades industriais. Contudo, o aumento da exploração e do transporte resulta em maiores acidentes ligados ao derramamento combustíveis, atingindo o solo e águas subterrâneas. Por ser um subproduto do petróleo, a principal constituição da gasolina são os hidrocarbonetos aromáticos, sendo em maior composição os compostos benzeno, tolueno, etilbenzeno e xileno, conhecido como BTEX. Este, quando em contato com o solo pode ser biodegradado por micro-organismos, principalmente os aeróbios previamente existentes naquela área. Para acelerar esse processo, podem ser utilizados aditivos biológicos com a função de estimular o crescimento e o metabolismo microbiano. Desse modo, este estudo teve como objetivo avaliar o processo de biorremediação de solos contaminados por hidrocarbonetos do petróleo, entre eles benzeno e tolueno, presentes em borra oleosa, e na substância tolueno em grau p.a.

\section{Palavras-chave:}

BTEX, aditivos biológicos, biorremediação.

\begin{abstract}
Introdução
Vários derrames acidentais e vazamentos de hidrocarbonetos de petróleo em solo são fontes persistentes de contaminação e causam riscos tanto ao ecossistema quanto a saúde humana. Em solos contaminados por resíduos ou derivados de petróleo, algumas substâncias se destacam em relação às demais, são elas: benzeno, tolueno, etilbenzeno e xileno, conhecidos como BTEX.

A biorremediação utiliza micro-organismos que estão presentes no solo ou adicionados na área contaminada com petróleo e seus derivados para que ocorra a degradação bioquímica dos contaminantes. Dessa forma, nesse projeto analisou-se a influência do aditivo biológico, denominado componente "B", na biodegradação de solos contaminados com resíduos de petróleo, contendo tolueno e benzeno.
\end{abstract}

\section{Resultados e Discussão}

Avaliou-se a biorremediação de borra oleosa em latossolo. Para isso, utilizou-se três diferentes fases da borra oleosa de petróleo, denominadas $A, B$ e $C$, cada uma com diferente viscosidade e densidade. A biodegradação da borra oleosa foi realizada pelo método de respirometria de Bartha e Pramer, que quantifica a geração de $\mathrm{CO}_{2}$ pelos micro-organismos do solo.

A Figura 1 expressa a geração acumulada de $\mathrm{CO}_{2}$ durante o período de 180 dias, a $28 \pm 2^{\circ} \mathrm{C}$, em estufa BOD.

Pode-se observar que no tratamento que analisou a biodegradação das três fases juntas e com a adição do componente $\mathrm{B}$, a biodegradação ocorreu de forma mais efetiva, observado pela maior quantidade de $\mathrm{CO}_{2}$ gerada ao longo do período analisado. Também foi possível verificar que o aditivo biológico estimulou a ação dos micro-organismos já presentes no solo em estudo.

Está sendo avaliado a biodegradação do tolueno, em sua composição p.a. no solo com as mesmas características, com a finalidade de verificar a biodegradação da sua fração em substância pura.
Figura 1. Geração acumulada de $\mathrm{CO}_{2}$ no processo de biodegradação em respirômetro de Bartha e Pramer, avaliado em 180 dias a $28 \pm 2^{\circ} \mathrm{C}$, em estufa BOD

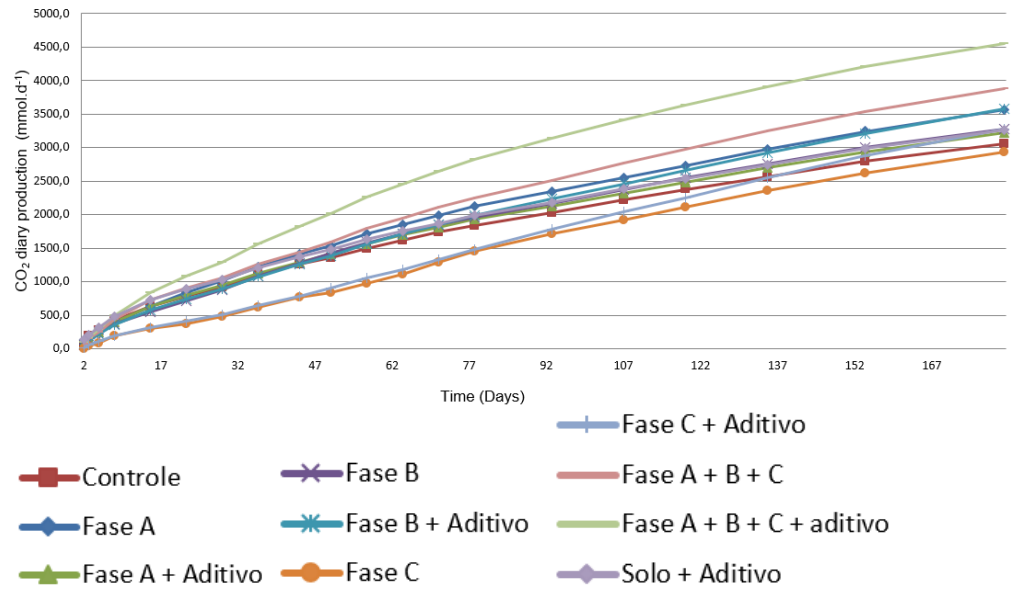

\section{Conclusões}

Pode-se concluir que o componente "B" se mostrou efetivo na biorremediação do solo contaminado pela borra oleosa, estimulando a microbiota do solo. Portanto, é vantajosa sua aplicação na recuperação de áreas contaminadas. Em relação ao tolueno, os resultados estão sendo finalizados para analisar o efeito do aditivo biológico na remediação do solo.

\section{Agradecimentos}

À minha orientadora, professora Cassiana Coneglian, pelo suporte, por suas correções e confiança; ao técnico do laboratório Gilberto Almeida, pelas orientações e auxílio e à FT- Faculdade de Tecnologia, pelo ambiente e por tornar possível este estudo.

BENTO, F.M.; CAMARGO, F.A.O.; OKEKE, B.; FRANKENBERGER JÚNIOR, W.T. Bioremediation of soil contaminated by diesel oil. Braz. J. Microbiol., 34:65-68, 2003.

OECD - ORGANIZATIONS FOR ECONOMIC CO-OPERATION AND DEVELOPMENT. Aerobic and Anaerobic Transformation in Soil. 24/04/2002 17p. (OECD Guideline for Testing of Chemicals - 307). 